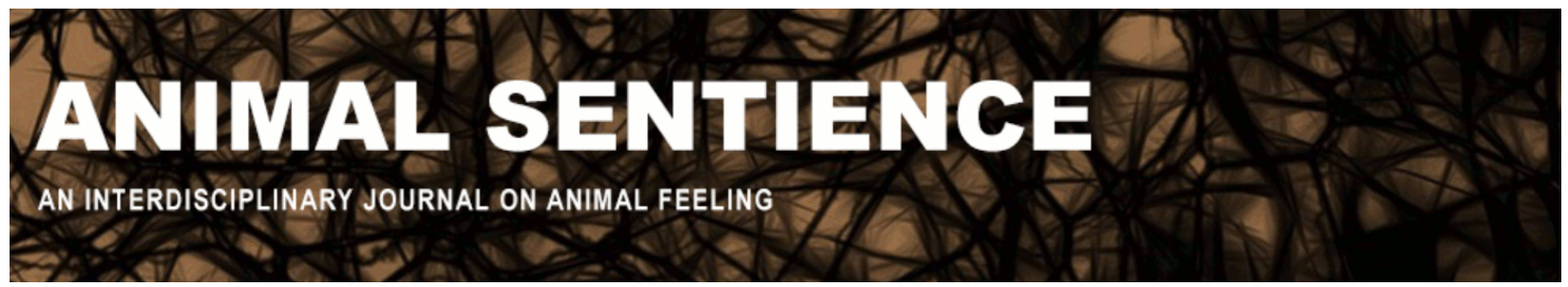

Brown, Culum (2016) Comparative evolutionary approach to pain perception in fishes. Animal Sentience 3(5)

DOI: $10.51291 / 2377-7478.1029$

Date of submission: 2015-09-24

Date of acceptance: 2015-12-11

(c)

This article has appeared in the journal Animal

Sentience, a peer-reviewed journal on animal

cognition and feeling. It has been made open access,

free for all, by WellBeing International and deposited

in the WBI Studies Repository. For more information,

please contact

wbisr-info@wellbeingintl.org.

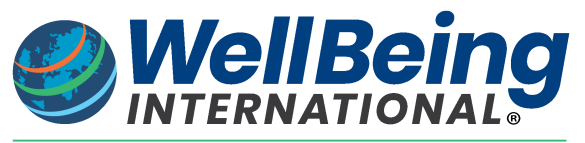

SOLUTIONS FOR PEOPLE, ANIMALS AND ENVIRONMENT 


\title{
Comparative evolutionary approach to pain perception in fishes
}

\author{
Commentary on Key on Fish Pain
}

\author{
Culum Brown \\ Biological Sciences \\ Macquarie University
}

\begin{abstract}
Arguments against the fact that fish feel pain repeatedly appear even in the face of growing evidence that they do. The standards used to judge pain perception keep moving as the hurdles are repeatedly cleared by novel research findings. There is undoubtedly a vested commercial interest in proving that fish do not feel pain, so the topic has a half-life well past its due date. Key (2016) reiterates previous perspectives on this topic characterised by a black-or-white view that is based on the proposed role of the human cortex in pain perception. I argue that this is incongruent with our understanding of evolutionary processes.
\end{abstract}

Keywords: pain, fishes, behaviour, physiology, nociception

\begin{abstract}
Culum Brown CulumBrown@yahoo.com studies the behavioural ecology of fishes with a special interest in learning and memory. He is Associate Professor of vertebrate evolution at Macquarie University, Co-Editor of the volume Fish Cognition and Behavior, and Editor for Animal Behaviour of the Journal of Fish Biology. https://sites.google.com/site/culumbrown/
\end{abstract}

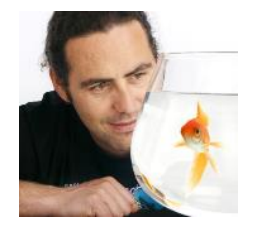

The question of whether teleost fish feel pain in a manner similar to humans is still hotly debated. The answer to this question has big implications not just for fish welfare, but also for the fishing and aquaculture industries. For this reason, the debate is often politicised. However, good science should not be directed or distracted by political interests.

In his target article on fish pain in Animal Sentience, Key (2016) lays out an argument as to why he believes fish do not feel pain - an argument very much along the lines of previous papers by Rose et al. (2014). Key approaches the question from a purely mechanistic perspective, relying on knowledge of the neuroanatomical structures that are believed to be responsible for pain perception in humans. His argument, however, is based on the assumption that all animals must process pain in the same way humans do if they are to experience pain in a similar fashion; most of the large body of comparative work showing functionally analogous and homologous structures across the broader vertebrate phylogeny is ignored. Evolution repeatedly throws up examples of convergent evolution in brain structure and function. Key's perspective is black or white: one must be conscious to feel pain, which is (arguably) a cortical process in humans. Thus any animal that does not have a cortex cannot feel pain. This perspective is inconsistent with the broader view of evolutionary processes that emphasises the spectrum of responses as traits evolve through common descent. Differences in mental faculties between vertebrate animals tend to be differences in degree rather than kind (Darwin 1859). 
In contrast, Sneddon et al. (2015) and I (Brown 2015) have argued from a behavioural ecology perspective that pain perception in vertebrate taxa is likely to have been an ancient evolutionary trait given the obvious fitness benefits it conveys to all animals. In this view the mechanical detection of noxious stimuli (nociception) cannot be usefully disentangled from the emotional (conscious) response to painful stimuli (pain). I do not disagree that fishes, like all vertebrates, have rapid, reflexive responses to potentially dangerous stimuli. These reflexes serve to immediately withdraw tissues and prevent further harm. However, the vast majority of animals also learn to associate painful stimuli with specific contexts or objects and therein lies the true value of pain perception. In learning these associations, animals can avoid dangerous objects or places in the future with all the obvious benefits that this entails. Thus animals must be cognitively engaged with pain perception if the long-term fitness benefits are to be realised.

Key seems to believe that the reason the broader scientific community accepts that fish feel pain is that it is more benevolent to do so. However, this position misses the fundamental argument for fish feeling pain, which is founded in part on the conservative nature of vertebrate evolution. If the rest of the vertebrates feel pain, then the most parsimonious hypothesis is that they do so because pain evolved deep in the evolutionary history of vertebrates (perhaps even before teleosts). Rather than to suppose that pain spontaneously arose somewhere else in the vertebrate lineage (e.g., between amphibians and reptiles), it is more parsimonious to infer that fish feel pain for the same reasons the rest of the vertebrates do. (By the way, from a phylogenetic perspective, all tetrapods are bony fishes!) Thus the emphasis of scientific investigation should be on proving that fish do not feel pain and coming up with a plausible evolutionary explanation for this lack. Until that is proven beyond doubt, our null position should be that fish do feel pain. Key himself concedes that we cannot "definitively prove" that fish do not feel pain. This fact is not mitigated by the further fact that it calls for a more humane treatment of animals, one that also happens to be more congruent with our "benevolent nature."

Key puts forward a typical human-centric argument focusing on the human pain structures and essentially argues that no such structures exist in fishes and thus fishes are incapable of feeling pain in the same way as humans. I hasten to add that this would apply to most vertebrates, not just fishes. This argument fails for three reasons: (1) it ignores mounting scientific evidence of homologous and analogous structures in the fish central nervous system including the brain; (2) it ignores the fact that the evolution of the vertebrate brain has repeatedly shown evidence of novel structures taking on ancient functions; and (3) according to the case studies Key supplies, human subjects with only residual traces of cortex still respond to pain on an emotional level. Thus, assuming that the human cerebral cortex is the magic bullet of pain perception in humans does not imply that all animals have to have a cortex to feel pain. The cortex has similarly taken on many other sensory perceptual functions that in other taxa had taken place in other parts of the brain. Pain perception in humans is not restricted to the cortex; rather, it is a whole brain function more reminiscent of the modern, extended neural network models of neural processing than local modular models (van den Heuval \& Sporns 2013).

There is some evidence that the signatures of pain can be detected in specific regions of the human cortex, but it does not follow that homologous regions do not exist in other animals. 
It is quite clear that even vestigial residue of cortical tissues is sufficient to subserve an emotional response to pain in human subjects; this strongly suggests that cortex-like tissues in other animals could perform a similar function. Despite years of intensive research, exactly how the human brain responds to pain is still open to debate and to date there is no widely accepted method of quantifying pain perception in humans let alone in other animals.

Key points to evidence in rodent models suggestive of structures analogous to the human cortical areas that are active during pain perception (Thompson \& Bushnell 2012). He interprets this as evidence that the cortex plays a role in pain perception in all vertebrates. However, rodents are mammals and are thus very closely related to humans. Based on this data, one might plausibly extend the hypothesis that the cortex is involved in pain perception to encompass all mammals (this still remains to be tested), but certainly not the vast majority of the vertebrate phylogeny. One might begin to address this issue constructively by looking for analogous or homologous structures in other vertebrates that have similar neural architecture. This is the approach that Key himself advocates, but for some reason he restricts himself almost entirely to data from humans and rats. His treatment of the fish literature is selective at best, and we hear very little about the rest of the vertebrates.

Conscious perception and various cognitive functions in humans typically involve the thalamocortical complex (Seth et al. 2005). While most vertebrates don't have this system in place, they still have functionally equivalent neuroanatomy. For example, birds do not possess an extensive cerebral cortex, but the avian pallium is structurally homologous (Medina \& Reiner 2000). Note that this is a classic example of convergent evolution. While the fish brain develops a little differently during ontogeny compared with the rest of the vertebrates, there is mounting evidence that the same structures are present in the fish brain (Rodriguez et al. 2011). For example, the lateral and medial pallia in fishes are homologous to the tetrapod hippocampus and amygdala, respectively. Lesions to the medial pallia disrupt emotional heart rate (fear) conditioning and avoidance learning (Broglio et al. 2005). The telencephalon (teleost forebrain) is also involved in avoidance learning (Overmier \& Papini 1986; Onishi 1997) and contains the emotional system that modulates fear conditioning (Portavella et al. 2003). Importantly, the telencephalon receives projections from the thalamus that mirror those seen in mammals (Rink \& Wullimann 2004) and painresponsive neurons are present in this structure (Dunlop \& Laming 2005).

Goldfish C1 and C2 fibres are functionally equivalent to mammalian C fibres including polymodal nociceptors; and the trigeminal nerve is dominated by $\mathrm{C} 1$ fibres as it is in mammals. It is interesting to note that $C$ fibres have not been found in elasmobranchs, but structures that perform similar functions presumably exist given their presence in agnathans (Snow et al. 1993). Collectively, it appears that fish possess the same route for noiciceptive afferent information as seen in mammals all the way from the periphery to the higher CNS. Mounting evidence further suggests that the telencephalon is the structure most likely to be involved in pain perception in fishes. The teleost pallial areas are responsible for higher order cognitive and emotional processing, and the dorsal lateral areas in particular resemble the tetrapod cortex (Rodriguez et al. 2011; Demski 2013). Moreover, fishes have similar ascending somatosensory pathways, opioid receptors, and endogenous opioids (Sneddon 2003, Sneddon 2004; Stoskopf 1994). 
While it is apparent that as the phylogenetic distance between animals increases, the number of homologous traits likely decreases, nevertheless the basic structure of neurons, synapses, neurotransmitters, and even patterns of connectivity resembling those of the human cortex remain the same (Baars 2005; Cottee 2010). One must conclude, therefore, that the similarities between the neuroanatomical structures involved in pain perception across all vertebrates far outweigh any perceived differences; this is a common signature of the conserved nature of the evolution of important developmental pathways (Edelman et al. 2005). The case is the same even in the absence of convergent evolution. This is one of the reasons why zebrafish are routinely used to understand any number of human disorders ranging from drug addiction to Alzheimer's disease (Lieschke \& Currie 2007).

Key is quick to dismiss behavioural evidence of pain as simply reflexive. In doing so he effectively writes off a hundred years of comparative psychology and behavioural ecology research. Entire fields of science are summarily dismissed. Behavioural research is the key to understanding the workings not just animal minds but our own. Much of child psychology is based on behavioural observations. There is ample behavioural evidence that fish show longterm, complex behaviour where they are clearly cognitively engaged with pain (see reviews by Chandroo et al. 2004; Braithwaite 2010; Cottee 2012; Sneddon et al. 2014; Brown 2015). Half a century ago, Agranoff et al. (1965) used a standard shuttle box to examine memory fixation in goldfish and found that injection with puromycin disrupts memory fixation as it does in mice. By changing the shock intensity, Gallon (1972) showed that the avoidance response by goldfish changes in a manner similar to dogs. Both of these papers clearly illustrate that the fishes' response to painful stimuli is not a simple reflex and is similar to mammals.

Long-term avoidance of locations and or stimuli associated with pain also provides evidence of non-reflexive behaviour. Hook-avoidance/shyness in fish, for example, can be retained for more than a year (Beukema 1970). Similarly, the ability to trade off between conflicting needs, such as avoiding noxious stimuli and staying close to conspecifics for safety, shows clear evidence of higher order processing of pain by fishes (Dunlop \& Laming 2005). Fish will also trade off access to food with the likelihood of receiving a shock (Millsopp \& Laming 2008). Self-medication following application of a painful stimulus by choosing a previously least preferred compartment that is now laced with pain killers is also firm evidence of cognitive engagement with painful stimuli (Sneddon 2012). Thus, although there are no doubts that some of the behavioural responses of fishes to noxious stimuli are reflexive (as they are in humans), there is a rich array of complex behaviours that illustrate cognitive processing of pain in higher parts of the fish brain, most notably the telencephalon (Rodriguiz et al. 2011; Brown 2015; Sneddon 2015).

Gregory (1999) proposed three-step criteria for objectively assessing if fish feel pain. First, we must establish that fish possess the neural architecture that other animals use to feel pain. Second, we must show that the responses to painful stimuli invoke changes in behaviour which can then be mitigated with analgesics. The last criterion is training fish to avoid aversive stimuli through associative learning. Science has clearly addressed the second and third criteria, and I would argue there is mounting evidence for the first. Although each piece of evidence can be explained away individually, the large body of convergent evidence 
from cross-disciplinary sources cannot be ignored. Even if we have doubts about any of these criteria, our fall-back position based on our understanding of evolutionary theory should be that fish do feel pain until proven otherwise. It just so happens that this position is also the most conservative one from an animal welfare perspective. Key himself concedes that we cannot prove that fish do not feel pain. It behoves us as human beings to treat all animals with respect and to minimise pain and suffering where we are able to do so. From a risk management perspective, the ethical costs of making an error in this judgement are huge given the massive number of fishes that are involved in fisheries and scientific research (Brown 2015).

\section{Acknowledgements}

Thanks to the many people who have partaken in active discussions in this interesting topic over the last 10 years.

\section{References}

Agranoff, B.W., Davis R.E. \& Brink J.J. (1965). Memory fixation in the goldfish. Proc. Natl. Acad. Sci., 54, 788-793.

Baars, B.J. (2005). Subjective experience is probably not limited to humans: the evidence from neurobiology and behavior. Conscious. Cogn., 14, 7-21.

Beukema, J.J. (1970). Angling experiments with carp (Cyprinus carpio L.) II. Decreasing catchability through one-trial learning. Netherlands Journal of Zoology, 20, 81-92.

Braithwaite, V. (2010). Do fish feel pain? New York, NY: Oxford University Press.

Broglio, C., Gómez, A., Durán, E., Ocańa, F.M., Jiménez-Moya, F., Rodríguez, R. \& Salas, C. (2005). Hallmarks of a common forebrain vertebrate plan: specialized pallial areas for spatial, temporal and emotional memory in actinopterygian fish. Brain Res. Bull., 66, 277-281.

Brown, C. (2015). Fish intelligence, sentience and ethics. Anim. Cogn., 18, 1-17.

Brown, C., Krause, J. \& Laland, K. (2011). Fish Cognition and Behavior. 2nd Edition. Oxford: Wiley-Blackwell.

Brown, C. (2015). Fish intelligence, sentience and ethics. Animal Cognition, 18, 1-17

Chandroo, K.P., Yue, S. \& Moccia, R.D. (2004). An evaluation of current perspectives on consciousness and pain in fish. Fish, 5, 1-15

Cottee, S.Y. (2012). Are fish the victims of 'speciesism'? A discussion about fear, pain and animal consciousness. Fish Physiology and Biochemistry, 38, 5-15. 
Darwin, C. (1859). Origin of species by means of natural selection or the preservation of favored races in the struggle for life. London: John Murray.

Demski, L.S. (2013). The pallium and mind/behavior relationships in teleost fishes. Brain Behav. Evol., 82, 31-44.

Dunlop, R. \& Laming, P. (2005). Mechanoreceptive and nociceptive responses in the central nervous system of goldfish (Carassius auratus) and trout (Oncorhynchus mykiss). J. Pain, 6, 561-568.

Edelman, D.B., Baars, B.J., Seth, A.K. (2005). Identifying hallmarks of consciousness in nonmammalian species. Conscious. Cogn., 14, 169-187.

Gallon, R. (1972). Effects of shock intensity on shuttlebox avoidance conditioning in goldfish. Psychol. Reports, 31, 855-858.

Gregory, N. (1999). Do fish feel pain? Aust. N. Z. Counc. Care Anim. Res. Teach. News, 12, 112.

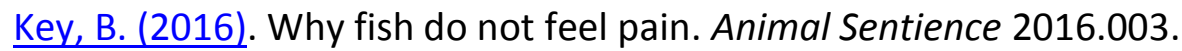

Lieschke, G.J. \& Currie, P.D. (2007). Animal models of human disease: zebrafish swim into view. Nat. Rev. Genet., 8, 353-367.

Medina, L. \& Reiner, A. (2000). Do birds possess homologues of mammalian primary visual, somatosensory and motor cortices? Trends Neurosci., 23, 1-12.

Millsopp, S. \& Laming, P. (2008). Trade-offs between feeding and shock avoidance in goldfish (Carassius auratus). Appl. Anim. Behav. Sci., 113, 247-254.

Onishi, K. (1997). Effects of telencephalic ablation on short-term memory and attention in goldfish. Behav. Brain Res., 86, 191-199.

Overmier, J.B. \& Papini, M.R. (1986). Factors modulating the effects of teleost telencephalon ablation on retention, learning and extinction of instrumental avoidance behaviour. Behav. Neuro., 100, 190-199.

Portavella, M., Salasa, C., Vargasa J.P. \& Papinic, M.R. (2003). Involvement of the telencephalon in spaced-trial avoidance learning in the goldfish (Carassius auratus) Physiol. Behav., 80, 49-56.

Rink, E. \& Wullimann, M. F. (2004). Connections of the ventral telencephalon (subpallium) in the zebrafish (Danio rerio). Brain Res., 1011, 206-220.

Rodríguez, R., Broglio, C., Durán, E., Gómez, A. \& Salas, C. (2011). Neural mechanisms of learning in teleost fish. In Cognition and Behavior 2nd Edition (pp. 243-277). Oxford: Wiley-Blackwell. 
Rose, J.D., Arlinghaus, R., Cooke, S. J., Diggles, B. K., Sawynok, W., Stevens, E. D. \& Wynne, C. D. L. (2014). Can fish really feel pain? Fish Fish., 15, 97-133.

Seth, A., Baars, B.J. \& Edelman, D.B. (2005). Criteria for consciousness in humans and other mammals. Conscious Cogn., 14, 119-139.

Sneddon, L.U. (2003). The evidence for pain in fish: The use of morphine as an analgesic. Applied Animal Behaviour Science, 83, 153-162

Sneddon, L.U. (2004). Evolution of nociception in vertebrates: comparative analysis of lower vertebrates. Brain Res. Brain Res. Rev., 46, 123-130.

Sneddon, L.U. (2015). Pain in aquatic animals. Journal of Experimental Biology 218, 967-976.

Sneddon, L.U., Elwood, R.W., Adamo, S. \& Leach, M.C. (2014). Defining and assessing animal pain. Anim. Behav., 97, 201-212.

Snow, P.J., Plenderleith, M.B. \& Wright, L.L. (1993). Quantitative study of primary sensory neurone populations of three species of elasmobranch fish. J. Comp. Neurol., 334, 97103.

Stoskopf, M.K. (1994). Pain, analgesia in birds, reptiles, amphibians, and fish. Invest. Opthalmol. Vis. Sci., 35, 775-780.

Thompson, S.J. \& Bushnell, M.C. (2012). Rodent functional and anatomical imaging of pain. Neurosci. Let., 520, 131-139.

Van den Heuvel, M.P. \& Sporns, O. (2013). Network hubs in the human brain. Trends. Cogn. Sci., 17, 683-696. 